\title{
KARAKTERISTIK MARSHALL \\ CAMPURAN HOT ROLLED SHEET WEARING COURSE MENGGUNAKAN BAHAN TAMBAH PLASTIK BEKAS JENIS POLYETHYLENE TEREPHTHALATE
}

\author{
Yusrizal Yahya \\ Fakultas Teknik \\ Universitas Palangka Raya \\ Jln. Yos Sudarso, Palangka Raya \\ Fax. (0536) 3226487 \\ yusrizalyahya23@gmail.com
}

\author{
Desriantomy \\ Fakultas Teknik \\ Universitas Palangka Raya \\ Jln.Yos Sudarso, Palangka Raya \\ Fax. (0536) 3226487 \\ desriantomy@yahoo.co.id
}

\author{
Robby \\ Fakultas Teknik \\ Universitas Palangka Raya \\ Jln.Yos Sudarso, Palangka Raya \\ Fax. (0536) 3226487 \\ robby_kalteng@yahoo.co.id
}

\begin{abstract}
This study was conducted to determine the benefits of the use of polyethylene terephthalate used plastic as additives in hot asphalt mixture Hot Rolled Sheet Wearing Course. Marshall testing was carried out on specimens using polyethylene terephthalate plastic additives, with variations in the ingredients added $2 \%, 4 \%$, $6 \%, 8 \%$, and $10 \%$ to the weight of asphalt on specimens with Optimum Asphalt Content. Marshall parameters of test specimens generally meet the existing specifications, except the Void In Mixture value for specimens with plastic content of $8 \%$ and $10 \%$. The optimum plastic content obtained from this study is $7.80 \%$.
\end{abstract}

Keywords: asphalt mixture, hot rolled sheet, Marshall parameters, polyethylene terephthalate

\begin{abstract}
Abstrak
Studi ini dilakukan untuk mengetahui manfaat penggunaan plastik bekas jenis Polyethylene Terephthalate sebagai bahan tambah pada campuran beraspal panas jenis Hot Rolled Sheet Wearing Course. Pengujian Marshall dilakukan terhadap benda-benda uji yang menggunakan bahan tambah plastik jenis Polyethylene Terephthalate, dengan variasi bahan tambah $2 \%, 4 \%, 6 \%, 8 \%$, dan $10 \%$ terhadap berat aspal pada benda uji dengan Kadar Aspal Optimum. Parameter Marshall benda-benda uji umumnya memenuhi spesifikasi yang ada, kecuali nilai Void In Mixture untuk benda-benda uji dengan kadar plastik 8\% dan 10\%. Kadar plastik optimum yang diperoleh dari studi ini adalah 7,80\%.
\end{abstract}

Kata-kata kunci: campuran beraspal, hot rolled sheet, parameter Marshall, polyethylene terephthalate

\section{PENDAHULUAN}

Salah satu jenis campuran yang digunakan pada perkerasan lentur adalah Lapis Tipis Aspal Beton (Lataston), yang bergradasi senjang dengan kadar aspal yang relatif tinggi (Gunaidi, 2012). Campuran ini akan menghasilkan jalan dengan kelenturan dan keawetan yang cukup baik, yang tidak menimbulkan kerusakan retak atau pelepasan butir, seperti yang sering terjadi pada Lapis Beton Aspal atau Laston (Nasution, 2017). Lataston sebagai lapis aus dikenal dengan nama Hot Rolled Sheet-Wearing Course (HRS-WC).

Banyak cara yang dapat dilakukan untuk meningkatkan kualitas perkerasan (Soehartono, 2015). Salah satu cara tersebut adalah dengan penggunaan bahan aditif ketika proses pencampuran aspal dan agregat di Asphalt Mixing Plant (AMP). Pada penelitian ini dilakukan pemanfaatan plastik bekas sebagai bahan tambah dalam campuran aspal, untuk 
mengetahui pengaruh penambahan plastik tersebut pada campuran beraspal panas $H o t$ Rolled Sheet-Wearing Course (HRS-WC), ditinjau dari karakteristik Marshall. Penambahan bahan plastik bekas ini diharapkan mampu meningkatkan kualitas campuran beraspal dan sekaligus sebagai suatu langkah penanganan sampah plastik.

Penelitian ini menggunakan metode uji laboratorium, untuk menganalisis penggunaan plastik bekas sebagai bahan tambah pada aspal dalam campuran Lataston Lapis Aus (Hot Rolled Sheet-Wearing Course). Pada penelitian di laboratorium diadakan pengamatan dan pemeriksaan terhadap proporsi campuran Lataston Lapis Aus (Hot Rolled Sheet-Wearing Course) yang memenuhi spesifikasi. Data yang dihasilkan digunakan untuk membuat rancangan campuran. Selanjutnya dibuat benda uji (briket) untuk dilakukan uji Marshall, sehingga diperoleh karakteristik campuran tersebut.

Pengambilan data dilakukan dengan membuat benda uji atau briket sebanyak 30 buah. Benda uji tersebut dibagi dalam 2 kali percobaan. Pada percobaan pertama dibuat 15 benda uji yang terdiri atas 1 macam komposisi terbaik yang mendekati spesifikasi dengan 5 variasi kadar aspal. Untuk tiap variasi kadar aspal dibuat 3 buah benda uji yang kemudian hasilnya dirata-ratakan untuk mendapatkan nilai Kadar Aspal Optimum (KAO). Pada percobaan kedua, KAO yang didapat pada percobaan pertama dipergunakan sebagai kadar aspal untuk memuat 15 buah benda uji, yang terdiri atas 5 variasi persentase berat plastik bekas terhadap berat aspal yang diperoleh dari KAO. Persentase berat plastik sebagai bahan tambah adalah $2 \%, 4 \%, 6 \%, 8 \%$, dan $10 \%$. Tiap variasi persentase berat plastik dibuat 3 buah benda uji.

\section{ANALISIS DAN PEMBAHASAN}

\section{Pengujian Sifat Fisik Agregat}

Pemeriksaan gradasi agregat kasar, pasir, dan abu batu dilakukan dengan uji analisis saringan yang hasilnya dapat dilihat pada Tabel 1. Selain itu, dilakukan pemeriksaan sifatsifat fisik agregat, yang berupa pemeriksaan berat jenis dan penyerapan agregat kasar dan agregat halus, serta pemeriksaan keausan (abrasi) agregat kasar. Hasil pemeriksaan sifatsifat fisik agregat ini dapat dilihat pada Tabel 2.

Tabel 1 Hasil Pemeriksaan Gradasi (Analisis Saringan)

\begin{tabular}{lcccc}
\hline \multirow{2}{*}{ No. Saringan } & \multicolumn{4}{c}{ Persentase Lolos Saringan (\%) } \\
\cline { 3 - 5 } & mm & Agregat Kasar (CA) & Abu Batu (FA) & Pasir (SA) \\
\hline Ukuran & 19 & 100,00 & 100,00 & 100,00 \\
$\# 3 / 4$ & 12,7 & 74,63 & 100,00 & 100,00 \\
$\# 3 / 2$ & 9,5 & 30,40 & 100,00 & 100,00 \\
No. 8 & 2,36 & 5,50 & 84,82 & 94,93 \\
No. 30 & 0,60 & 2,37 & 56,71 & 58,83 \\
No. 200 & 0,075 & 0,77 & 13,06 & 11,73 \\
\hline
\end{tabular}


Tabel 2 Hasil Pemeriksaan Sifat-Sifat Fisik Agregat

\begin{tabular}{lccc}
\hline \multirow{2}{*}{ Pemeriksaan } & \multicolumn{2}{c}{ Eks. Palu } & \multirow{2}{*}{ Pasir Tangkiling } \\
\cline { 2 - 3 } & Agregat Kasar & Abu Batu & \\
\hline Berat Jenis (gram/ $\left.\mathrm{cm}^{3}\right)$ & 2,654 & 2,531 & 2,507 \\
Berat Jenis Kering Permukaan/SSD & 2,691 & 2,578 & 2,556 \\
$\left(\right.$ gram/ $\left.\mathrm{cm}^{3}\right)$ & & & \\
Berat Jenis Semu (gram/ $\left./ \mathrm{cm}^{3}\right)$ & 2,758 & 2,654 & 2,636 \\
Penyerapan $(\%)$ & 1,430 & 1,834 & 1,972 \\
Keausan/Abrasi (\%) & 23,450 & - & - \\
Sand Equivalent $(\%)$ & - & - & 64,83 \\
\hline
\end{tabular}

\section{Perancangan Campuran}

Perancangan campuran dilakukan dengan menggunakan Metode Asphalt Institute dan perhitungan penggabungan agregat menggunakan Cara Diagonal. Selanjutnya gradasi agregat gabungan dikontrol menggunakan cara coba-coba (trial and error) atau yang mendekati spesifikasi yang ideal. Proporsi untuk cara coba-coba ini disajikan pada Tabel 3.

Tabel 3 Hasil Perhitungan Gradasi Gabungan Cara Trial and Error

\begin{tabular}{|c|c|c|c|c|c|c|c|c|c|}
\hline \multicolumn{2}{|c|}{ No. Saringan } & \multicolumn{2}{|c|}{ Agregat Kasar (CA) } & \multicolumn{2}{|c|}{ Abu Batu (FA) } & \multicolumn{2}{|c|}{ Pasir (SA) } & \multirow{2}{*}{$\begin{array}{c}\text { Total } \\
\text { Kombinasi }\end{array}$} & \multirow{2}{*}{ Spesifikasi } \\
\hline Inci & $\mathrm{Mm}$ & $100 \%$ & $32 \%$ & $100 \%$ & $34 \%$ & $100 \%$ & $34 \%$ & & \\
\hline$\# 3 / 4$ & 19,0 & 100,00 & 32,00 & 100,00 & 34,00 & 100,00 & 34,00 & 100,00 & 100 \\
\hline$\# 1 / 2$ & 12,7 & 74,63 & 23,88 & 100,00 & 34,00 & 100,00 & 34,00 & 91,88 & $90-100$ \\
\hline \#3/8 & 9,5 & 30,40 & 9,73 & 100,00 & 34,00 & 100,00 & 34,00 & 77,73 & $75-85$ \\
\hline No. 8 & 2,36 & 5,50 & 1,76 & 84,77 & 28,82 & 94,93 & 32,28 & 62,86 & $50-72$ \\
\hline No. 30 & 0,600 & 2,37 & 0,76 & 56,57 & 19,23 & 58,83 & 20,00 & 39,99 & $35-60$ \\
\hline No. 200 & 0,075 & 0,77 & 0,25 & 12,77 & 4,34 & 11,73 & 3,99 & 8,58 & $6-10$ \\
\hline
\end{tabular}

Dari hasil perhitungan komposisi campuran yang sudah didapat, nilai total kombinasi dapat digunakan untuk menentukan perkiraan kadar aspal awal. Perkiraan kadar aspal awal diperoleh dengan menggunakan Persamaan 1.

$$
\mathrm{Pb}=0,035(\% \mathrm{CA})+0,045(\% \mathrm{FA})+0,18(\% \text { Filler })+\text { Konstanta }
$$

dengan:

$\mathrm{Pb} \quad=$ Kadar aspal;

$\mathrm{CA} \quad=$ Agregat kasar;

FA $\quad=$ Agregat halus;

Filler = Agregat halus lolos saringan No. 200; dan

Konstanta $=2,0-3,0$ (untuk studi ini digunakan nilai konstanta sebesar 2,0).

Dengan menggunakan persamaan tersebut diperoleh kadar aspal $\mathrm{Pb}$ sebesar 7,29\% atau dibulatkan menjadi 7,5\% terhadap berat total agregat. Selanjutnya ditentukan 2 variasi kadar aspal di bawah dan 2 variasi kadar aspal di atas nilai $\mathrm{Pb}$, dengan interval 0,5\%. Kelima variasi kadar aspal tersebut adalah 6,5\%,7\%,7,5\%,8\%, dan 8,5\%. Berat total agregat yang digunakan adalah 1.200 gram. 
Berdasarkan komposisi yang telah ditetapkan, dilakukan perhitungan berat material dan aspal untuk pembuatan benda uji. Rancangan berat material dan aspal dapat dilihat pada Tabel 4.

Tabel 4 Rancangan Komposisi Campuran

\begin{tabular}{|c|c|c|c|c|c|c|c|c|c|c|}
\hline \multirow{2}{*}{\multicolumn{5}{|c|}{ Berat Total Agregat 1.200 gram }} & \multirow{4}{*}{$\begin{array}{c}\text { Berat } \\
\text { Total } \\
\text { Agregat } \\
\text { Campuran } \\
\text { gram }\end{array}$} & \multicolumn{4}{|c|}{ Variasi Kadar Aspal } & \multirow{4}{*}{$\begin{array}{l}\text { Kode } \\
\text { Sampel }\end{array}$} \\
\hline & & & & & & $6,5 \%$ & $7,5 \%$ & $8,0 \%$ & $8,5 \%$ & \\
\hline $\begin{array}{c}\text { Agregat } \\
\text { Kasar }\end{array}$ & & Batu & & $\operatorname{sir}$ & & \multicolumn{4}{|c|}{$\begin{array}{c}\text { Berat Kadar Aspal terhadap } \\
\text { Total Campuran }\end{array}$} & \\
\hline gram & $\%$ & gram & $\%$ & gram & & & gram & & & \\
\hline 384 & 34 & 408 & 34 & 408 & 1.200 & 90,3 & 97,3 & 104,3 & 111,5 & $\mathrm{I}$ \\
\hline
\end{tabular}

\section{Pengujian Marshall}

Hasil dari pengujian Marshall di laboratorium dapat dilihat pada Tabel 5. Hasil pengujian Marshall I ini menunjukkan bahwa semua parameter Marshall pada campuran beraspal dengan kadar aspal 7\% dan 7,5\% memenuhi spesifikasi, sedangkan beberapa parameter Marshall pada campuran beraspal dengan kadar aspal 6,5\%,8,0\%, dan 8,5\% tersebut tidak memenuhi spesifikasi.

Tabel 5 Hasil Pengujian Parameter Karakteristik Marshall

\begin{tabular}{ccccccc}
\hline \multirow{2}{*}{$\begin{array}{c}\text { Kadar } \\
\text { Aspal } \\
(\%)\end{array}$} & $\begin{array}{c}\text { Stabilitas } \\
(\mathrm{kg})\end{array}$ & $\begin{array}{c}\text { Flow } \\
(\mathrm{mm})\end{array}$ & $\begin{array}{c}\text { VIM } \\
(\%)\end{array}$ & $\begin{array}{c}\text { VFB } \\
(\%)\end{array}$ & $\begin{array}{c}\text { MQ } \\
(\mathrm{kN} / \mathrm{mm})\end{array}$ & Keterangan \\
\hline 6,5 & 825,926 & 2,80 & 7,42 & 65,57 & 295,217 & $\begin{array}{c}\text { Flow, VIM, dan VFB } \\
\text { Tidak Memenuhi }\end{array}$ \\
& & & & & & Memenuhi \\
7,0 & 906,446 & 3,10 & 5,91 & 72,40 & 293,223 & Memenuhi \\
7,5 & 973,449 & 3,23 & 4,20 & 80,05 & 300,817 & VIM Tidak Memenuhi \\
8,0 & 860,340 & 3,03 & 3,64 & 83,16 & 283,667 & Varameter Karakteristik Marshall \\
8,5 & 833,058 & 3,00 & 2,98 & 86,62 & 278,659 & VIM Tidak Memenuhi \\
Spesifikasi & $>800$ & $>3,00$ & $4-6$ & $>68$ & $>250$ & \\
\hline
\end{tabular}

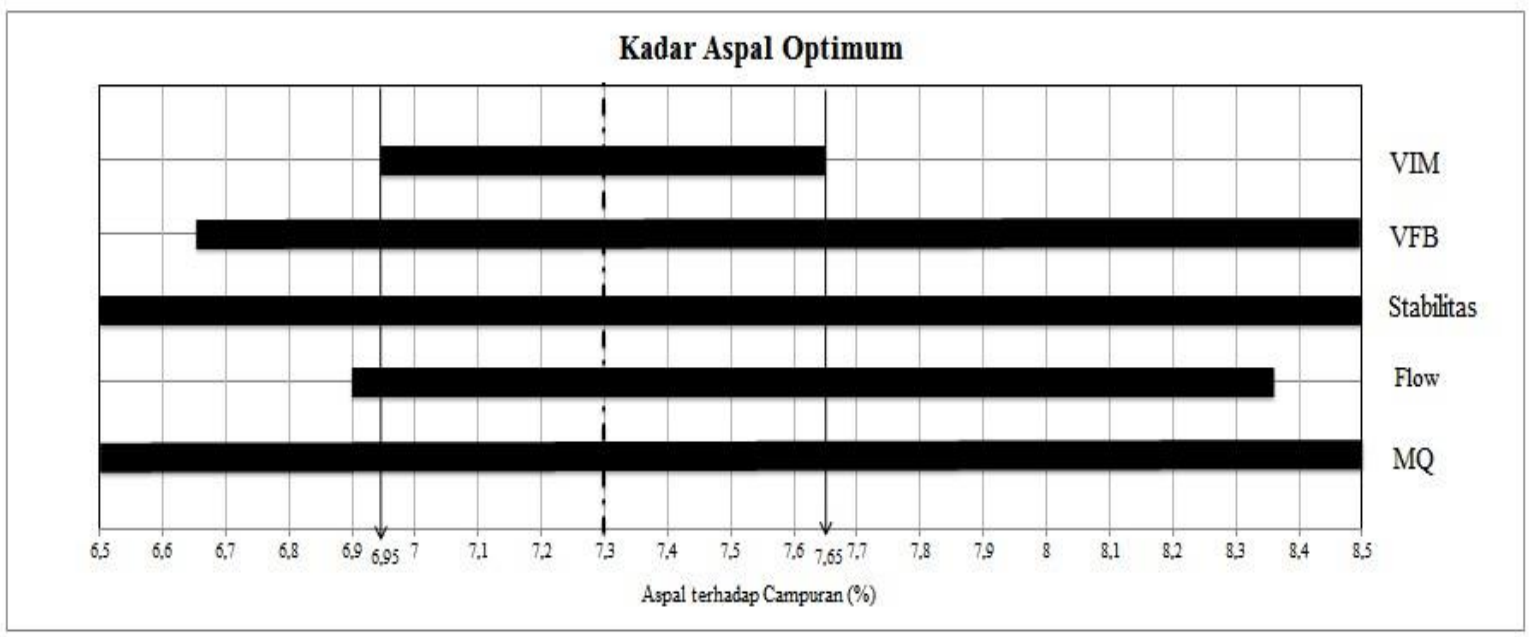

Gambar 1 Hubungan Kadar Aspal dengan Parameter Marshall 
Hasil evaluasi sifat karakteristik Marshall menunjukkan bahwa pada rentang kadar aspal $6,95 \%$ hingga $7,65 \%$, campuran memenuhi semua persyaratan yang ditentukan (Gambar 1). Berdasarkan rentang tersebut diambil nilai tengah rentang, yaitu 7,30\% sebagai nilai KAO. Hasil nilai parameter Marshall dengan KAO dapat dilihat pada Tabel 6.

Tabel 6 Nilai Parameter Karakteristik Marshall pada Kadar Aspal Optimum (KAO)

\begin{tabular}{|c|c|c|c|c|c|c|}
\hline \multirow[b]{2}{*}{$\begin{array}{l}\text { Komposisi } \\
\text { Campuran }\end{array}$} & \multirow[b]{2}{*}{$\begin{array}{l}\text { KAO } \\
(\%)\end{array}$} & \multicolumn{5}{|c|}{ Parameter Karakteristik Marshall } \\
\hline & & $\begin{array}{c}\text { Stabilitas } \\
(\mathrm{kg})\end{array}$ & $\begin{array}{l}\text { Flow } \\
\text { (mm) }\end{array}$ & $\begin{array}{c}\text { Rongga dalam } \\
\text { Campuran } \\
(\%)\end{array}$ & $\begin{array}{c}\text { Rongga Terisi } \\
\text { Aspal } \\
(\%)\end{array}$ & $\begin{array}{c}\text { Hasil Bagi } \\
\text { Marshall } \\
(\mathrm{kg} / \mathrm{mm})\end{array}$ \\
\hline I & 7,30 & 932,00 & 3,15 & 4,90 & 76,2 & 293,00 \\
\hline Spesifikasi & - & $>800$ & $>3$ & $4-6$ & $>68$ & $>250$ \\
\hline
\end{tabular}

\section{Pengujian Marshall dengan Bahan Tambah Plastik Polyethylene Terephthalate}

Setelah diperoleh nilai KAO, dilakukan percobaan dengan menggunakan bahan tambah plastik bekas jenis Polyethylene Terephthalate (PET) dengan variasi kadar bahan tambah yang sudah direncanakan dan dengan komposisi agregat yang sama dengan komposisi campuran yang menggunakan KAO. Rancangan komposisi campuran ini dapat dilihat pada Tabel 7.

Tabel 7 Rancangan Komposisi Campuran dengan Bahan Tambah Plastik

\begin{tabular}{ccccccc}
\hline $\begin{array}{c}\text { Berat } \\
\text { Total } \\
\begin{array}{c}\text { Agregat } \\
\text { Campuran } \\
(\text { gram })\end{array}\end{array}$ & $\begin{array}{c}\text { Persentase dan } \\
\text { Berat Aspal } \\
\text { terhadap Berat } \\
\text { Total Campuran } \\
(\%)\end{array}$ & $\begin{array}{c}\text { Persentase } \\
\text { Plastik } \\
\text { terhadap }\end{array}$ & $\begin{array}{c}\text { Berat Plastik } \\
\text { Aspal (KAO) }\end{array}$ & $\begin{array}{c}\text { terhadap } \\
\text { Berat } \\
\text { Aspal (KAO) }\end{array}$ & $\begin{array}{c}\text { Berat } \\
\text { Total } \\
\text { Campuran }\end{array}$ & $\begin{array}{c}\text { Kode } \\
\text { Sampel }\end{array}$ \\
\hline 1.200 & 7,30 & 94,50 & 2,00 & 1,89 & 1296,39 & $\mathrm{~A}$ \\
1.200 & 7,30 & 94,50 & 4,00 & 3,78 & 1298,28 & $\mathrm{~B}$ \\
1.200 & 7,30 & 94,50 & 6,00 & 5,67 & 1300,17 & $\mathrm{C}$ \\
1.200 & 7,30 & 94,50 & 8,00 & 7,56 & 1302,06 & $\mathrm{D}$ \\
1.200 & 7,30 & 94,50 & 10,00 & 9,45 & 1303,95 & $\mathrm{E}$ \\
\hline
\end{tabular}

Tabel 8 Hasil Pengujian Karakteristik Marshall dengan Bahan Tambah Plastik

\begin{tabular}{ccccccc}
\hline \multirow{2}{*}{$\begin{array}{c}\text { Kadar } \\
\text { Aspal } \\
(\%)\end{array}$} & $\begin{array}{c}\text { Stabilitas } \\
(\mathrm{kg})\end{array}$ & $\begin{array}{c}\text { Flow } \\
(\mathrm{mm})\end{array}$ & $\begin{array}{c}\text { VIM } \\
(\%)\end{array}$ & $\begin{array}{c}\text { VFB } \\
(\%)\end{array}$ & $\begin{array}{c}\text { MQ } \\
(\mathrm{kN} / \mathrm{mm})\end{array}$ & Keterangan \\
\hline 0,0 & 932,000 & 3,15 & 4,90 & 76,20 & 293,000 & Hasil Marshall I \\
2,0 & 961,756 & 3,17 & 5,10 & 76,10 & 303,532 & Memenuhi \\
4,0 & 973,946 & 3,23 & 4,36 & 78,97 & 301,137 & Memenuhi \\
6,0 & 994,843 & 3,33 & 4,15 & 79,95 & 298,249 & Memenuhi \\
8,0 & $1.012,672$ & 3,42 & 3,90 & 80,81 & 297,429 & VIM Tidak \\
& & & & & & Memenuhi \\
10,0 & $1.019,803$ & 3,46 & 3,77 & 81,33 & 294,985 & VIM Tidak \\
& & & & & & Memenuhi \\
Spesifikasi & $>800$ & $>3,00$ & $4-6$ & $>68$ & $>250$ & \\
\hline
\end{tabular}

Hasil pengujian Marshall pada percobaan Marshall II, untuk campuran dengan variasi persentase bahan tambah plastik, disajikan pada Tabel 8. Hasil pengujian Marshall II 
ini menunjukkan bahwa pada penambahan plastik ke dalam campuran dengan persentase $2 \%$, 4\%, dan $6 \%$ terhadap berat aspal dari KAO, campuran aspal tersebut memenuhi Spesifikasi Parameter Marshall yang terdapat pada Spesifikasi Umum Bina Marga Tahun 2010 Revisi 3. Sedangkan untuk penambahan plastik dengan persentase $8 \%$ dan $10 \%$, nilai parameter Marshall rongga dalam campuran (VIM) tidak memenuhi spesifikasi. Nilai rongga dalam campuran (VIM) untuk benda uji dengan persentase bahan tambah $8 \%$ dan $10 \%$ berturut-turut, adalah $3,90 \%$ dan $3,77 \%$. Nilai-nilai ini lebih kecil daripada yang disyaratkan oleh Spesifikasi Bina Marga Tahun 2010 Revisi 3, sebesar 4\% hingga 6\%.

Dari hasil evaluasi sifat fisik benda uji pada percobaan Marshall II, dapat ditunjukkan rentang kadar penambahan bahan plastik, seperti terlihat pada Gambar 2. Hasil evaluasi terhadap karakteristik Marshall menunjukan bahwa pada rentang penambahan kadar plastik $0 \%$ hingga $7,80 \%$, campuran memenuhi semua persyaratan yang ditentukan. Berdasarkan rentang tersebut diambil nilai kadar penambahan plastik optimum, berdasarkan pada nilai parameter Marshall yang memenuhi semua persyaratan spesifikasi yang telah ditentukan dan yang menghasilkan nilai stabilitas tertinggi. Nilai kadar plastik optimum yang didapat adalah 7,80\%. Dari pengujian diperoleh nilai parameter Marshall dengan kadar plastik optimum $7,80 \%$, seperti yang dapat dilihat pada Tabel 9 .

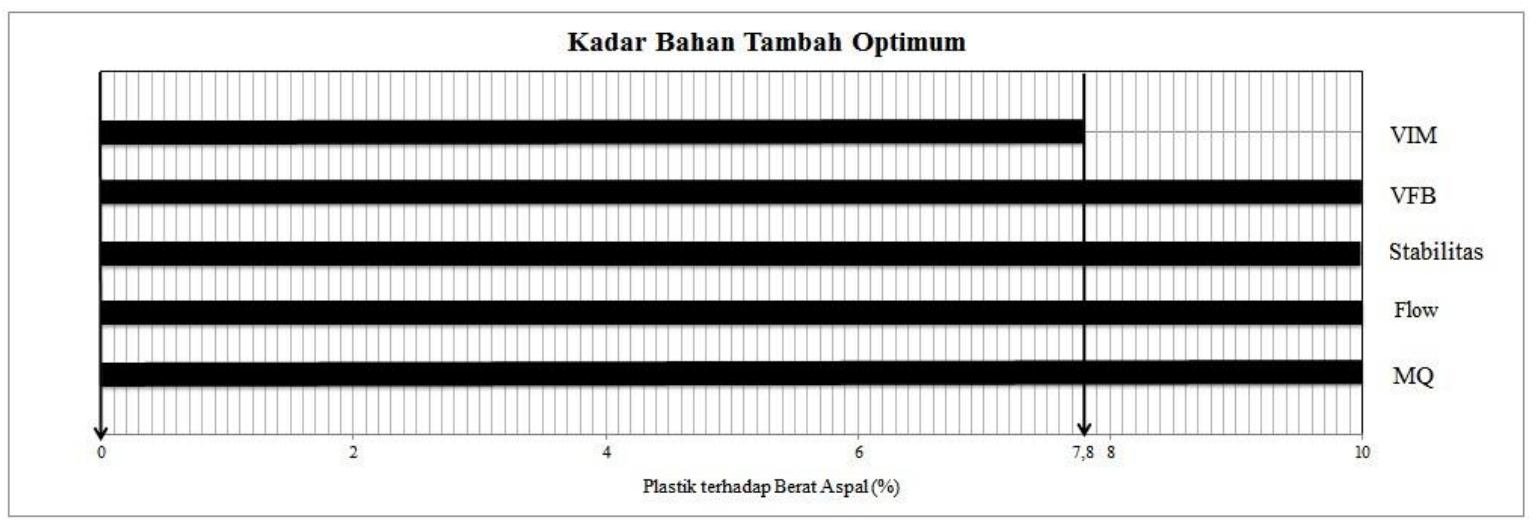

Gambar 2 Hubungan Parameter Marshall dengan Kadar Bahan Plastik

Tabel 9 Nilai Parameter Marshall pada Kadar Aspal Optimum

\begin{tabular}{clccc}
\hline No. & Karakteristik Marshall & Nilai & Persyaratan & Satuan \\
\hline 1 & Stabilitas & 1010 & 800 & $\mathrm{~kg}$ \\
2 & Flow & 3,40 & $\geq 3$ & $\mathrm{~mm}$ \\
3 & VIM & 4,20 & $4-6$ & $\%$ \\
4 & VFB & 80,50 & $\geq 68$ & $\%$ \\
5 & Hasil Bagi Marshall & 297,50 & $\geq 250$ & $\mathrm{~kg} / \mathrm{mm}$ \\
\hline
\end{tabular}

Pada Tabel 10 dapat dilihat bahwa penambahan plastik jenis PET sebesar 7,80\% terhadap berat aspal pada KAO, meningkatkan nilai stabilitas sebesar 8,37\%, atau $78 \mathrm{~kg}$, dibandingkan stabilitas campuran tanpa menggunakan bahan tambah plastik. Nilai flow campuran juga naik sebesar $0,25 \mathrm{~mm}$, rongga dalam campuran turun sebesar $0,60 \%$, rongga terisi aspal naik sebesar 4,30\%, dan hasil bagi Marshall naik sebesar 4,50 kg/mm. 
Tabel 10 Perbandingan Nilai Parameter Masrshall Campuran Tanpa Plastik dan Dengan Menggunakan Penambahan Plastik Optimum

\begin{tabular}{|c|c|c|c|c|c|c|}
\hline \multirow[b]{2}{*}{$\begin{array}{l}\text { Komposisi } \\
\text { Campuran }\end{array}$} & \multirow[b]{2}{*}{$\begin{array}{c}\text { Kadar } \\
\text { Plastik } \\
(\%)\end{array}$} & \multicolumn{5}{|c|}{ Parameter Karakteristik Marshall } \\
\hline & & $\begin{array}{c}\text { Stabilitas } \\
(\mathrm{kg})\end{array}$ & $\begin{array}{l}\text { Flow } \\
\text { (mm) }\end{array}$ & $\begin{array}{c}\text { Rongga dalam } \\
\text { Campuran } \\
(\%)\end{array}$ & $\begin{array}{c}\text { Rongga Terisi } \\
\text { Aspal } \\
(\%)\end{array}$ & $\begin{array}{c}\text { Hasil Bagi } \\
\text { Marshall } \\
(\mathrm{kg} / \mathrm{mm})\end{array}$ \\
\hline $\mathrm{I}$ & 0,00 & 932,00 & 3,15 & 4,90 & 76,20 & 293,00 \\
\hline II & 7,80 & 1010,00 & 3,40 & 4,20 & 80,50 & 297,50 \\
\hline Spesifikasi & - & $>800$ & $>3$ & $4-6$ & $>68$ & $>250$ \\
\hline
\end{tabular}

\section{KESIMPULAN}

Berdasarkan studi ini dapat ditarik kesimpulan sebagai berikut:

1) Hasil penelitian pendahuluan terhadap parameter Marshall dengan variasi kadar aspal 6,5\%, 7,0\%, 7,5\%, 8,0\%, dan 8,5\% memberikan Kadar Aspal Optimum (KAO) sebesar $7,30 \%$.

2) Campuran beraspal yang menggunakan $\mathrm{KAO} 7,30 \%$ dan bahan tambah plastik jenis Polyethylene Terephthalate (PET), dengan variasi kadar bahan tambah plastik sebesar $2 \%, 4 \%, 6 \%, 8 \%$, dan $10 \%$ terhadap berat aspal optimum, mempunyai parameter Marshall sebagai berikut:

a) Nilai stabilitas untuk semua variasi kadar bahan tambah plastik memenuhi spesifikasi yang disyaratkan. Nilai stabilitas tertinggi terdapat pada campuran dengan kadar plastik 10\%, yaitu sebesar 1.019,803 kg. Nilai Stabilitas yang dihasilkan meningkat seiring dengan penambahan plastik.

b) Nilai kelelehan (flow) untuk semua variasi kadar bahan tambah plastik memenuhi spesifikasi yang disyaratkan. Nilai flow tertinggi terdapat pada campuran dengan kadar plastik $10 \%$, yaitu sebesar 3,46 mm. Nilai flow meningkat seiring dengan meningkatnya kadar plastik.

c) Nilai rongga udara dalam campuran (VIM) untuk variasi kadar bahan tambah plastik $2 \%, 4 \%$, dan $6 \%$ memenuhi spesifikasi dan untuk variasi kadar bahan tambah plastik $8 \%$ dan $10 \%$ tidak memenuhi spesifikasi. Nilai VIM tertinggi yang memenuhi spesifikasi terdapat pada campuran dengan kadar plastik $2 \%$, yaitu sebesar 5,10\%. Nilai rongga dalam campuran (VIM) yang dihasilkan cenderung menurun dengan meningkatnya kadar plastik.

d) Nilai rongga terisi aspal (VFB) untuk semua variasi kadar bahan tambah plastik memenuhi spesifikasi yang disyaratkan. Nilai rongga terisi aspal (VFB) tertinggi terdapat pada campuran dengan kadar plastik $10 \%$, yaitu sebesar $81,33 \%$. Nilai rongga terisi aspal meningkat seiring dengan persentase kadar plastik.

e) Nilai hasil bagi Marshall untuk semua benda uji dengan berbagai variasi bahan tambah plastik memenuhi spesifikasi yang disyaratkan. Nilai hasil bagi Marshall tertinggi terdapat pada campuran dengan kadar plastik 2,0\%, yaitu sebesar 303,532 
$\mathrm{kg} / \mathrm{mm}$ dan nilai terendah terdapat pada campuran dengan kadar plastik $10 \%$, yaitu sebesar 294,985 kg/mm.

3) Kadar plastik optimum yang diperoleh dari studi ini adalah 7,80\%. Nilai parameter karakteristik Marshall pada KAO dan penambahan plastik pada kadar plastik optimum menghasilkan stabilitas sebesar $1.010 \mathrm{~kg}$, flow sebesar 3,40 mm, rongga dalam campuran (VIM) sebesar 4,20\%, rongga terisi aspal (VFB) sebesar 80,50\%, dan hasil bagi Marshall (MQ) sebesar 297,50 kg/mm.

4) Penambahan plastik jenis PET sebesar $7,80 \%$ terhadap berat aspal. Dengan kadar plastik ini, nilai stabilitas naik $8,37 \%$ atau $78 \mathrm{~kg}$ dibandingkan nilai stabilitas campuran tanpa menggunakan bahan tambah plastik. Sementara itu, flow naik sebesar 0,25 mm, rongga dalam campuran (VIM) turun sebesar $0,60 \%$, rongga terisi aspal (VFB) naik sebesar 4,30\%. dan hasil bagi Marshall naik sebesar 4,50 kg/mm.

\section{DAFTAR PUSTAKA}

Gunaidi, M.A.D. 2012. Analisis Karakteristik Campuran Aspal Beton Lapis Aus (AC-WC) dengan Menggunakan Plastik Bekas Sebagai Bahan Pengganti Sebagian Agregat. Tugas Akhir tidak diterbitkan. Denpasar: Fakultas Teknik, Universitas Udayana.

Kementerian Pekerjaan Umum. 2014. Spesifikasi Umum 2010 Revisi 3. Jakarta.

Nasution, M.F.N. 2017. Pengaruh Penambahan Plastik PET (Polyethylene Terephthalate) terhadap Karakteristik Campuran AC-WC di Laboratorium. Tugas Akhir tidak diterbitkan. Medan: Fakultas Teknik Universitas Sumatera Utara.

Soehartono. 2015. Teknologi Aspal dan Penggunaannya dalam Konstruksi Perkerasan Jalan. Yogyakarta: Andi Offset. 